\title{
Some Chemical Properties of Infrared Dried Neem Fruit in Turkey
}

\author{
Tunahan Erdem ${ }^{1, a, *}$ \\ ${ }^{I}$ Department of Agricultural Machinery and Technologies Engineering, Faculty of Agriculture, Çukurova University, 01330 Adana, Turkey \\ ${ }^{*}$ Corresponding author

\begin{tabular}{l|l}
\hline A R T I C L E I N F O & A B S T R A C T \\
\hline Research Article & $\begin{array}{l}\text { In Turkey, the Rosary (Neem) tree, known as the Melia azedarach L. is a type of evergreen plant. In } \\
\text { the world, four different species of tree grows native in India, Burma, Pakistan, South Asia, and } \\
\text { Australia. In our country, the Neem tree (Melia azedarach L.) grows naturally in tropical zones with } \\
\text { light yellow fruit and green leaves. Fruits can reach maturity in September-October morphologically. } \\
\text { Neem oil from fruits and powder from fruits and leaves are the main products which are traded in } \\
\text { abroad as organic substances. In this study, neem fruit was investigated to obtain the neem oil from } \\
\text { Melia azedarach L. in details such as moisture content (MC), drying rate (DR), moisture ratio (MR), } \\
\text { Azadirachtin amount (AZ) and macro and microelement parameters. The fruits were collected from } \\
\text { locally Turkey and de moisturized in the greenhouse for one week than dried in Infrared cabinet } \\
\text { dryer to obtain the neem oil. The Azadirachtin amount results were found 46.1; 45.4; 48.4 (mg/g) } \\
\text { through three replications. }\end{array}$ \\
$\begin{array}{l}\text { Keywords: } \\
\text { Azadirachtin }\end{array}$ & $\begin{array}{l}\text { Drying }\end{array}$
\end{tabular}

Neem fruit

Herbicide

Organic fertilizer

terdem@cu.edu.tr

(iD)https://orcid.org/0000-0002-1595-6852

(c) (1) () T) This work is licensed under Creative Commons Attribution 4.0 International License

\section{Introduction}

Melia azedarach L. is a deciduous tree up to $45 \mathrm{~m}$ tall; bole fluted below when old, up to $30-60$ (max. 120) $\mathrm{cm}$ in diameter, with a spreading crown and sparsely branched limbs. Bark smooth, greenish-brown when young, turning grey, and fissured with age (Orwa et al., 2009). Melia azedarach belongs to the Meliaceae family, and there are four other spices which grow naturally in Pakistan, India, Myanmar, and Australia. It contents like azadirachtin (AZ), salanin, meliantriol, nimbin, nimbidin and many fatty acids like oleic, palmitic and linoleic acids exist in the leaves, roots, fruits, seeds, and barks of $M$. azedarach (Skhellon et al., 1962). Azadirachtin is the most important part that plays an important role in bio-based farm production. It has been reported that azadirachtin substances are effective on over 600 insects, some fungus, and weed (Anonymous, 2012). Neem oil is widely used as insecticides, lubricant, drugs for a variety of diseases such as diabetes and tuberculosis (Puri, 1999).

Melia Azaderach L. is a different seed structure (Fig. 1) than the other spices. Therefore it contains lower fixed oil. The oil yield obtained from spices varies because of the harvest time and temperature as well.
In our country Melia azedarach which grows in the seacoastal area of Turkey. It is widespread of Adana, Hatay, Mersin, Antalya, İzmir and Aydın province. It grows 800 $m$ altitude from sea level. Neem seed is a part of the Neem tree which has neem oil. Neem oil is used as a bioinsecticide, pesticide, and as fungicide and its usage grown more on more because of the high demand for organic-farm based product. Turkey is imported the neem oil from abroad, and its usage is limited because of the high oil price. On the other hand, the country has Melia azedarach tress, which gives the possibility of neem oil production. However, the azadirachtin amount of neem oil plays a more important role to produce an effective bio-based product. Neem fruits are also used as fruit powder or neem cake, which is residue from the oil process. Neem cake has an adequate quantity of Nitrogen (N), Phosphorus (P), and Potassium (K) in organic form for plant growth. Being a totally botanical product it contains $100 \%$ of natural $\mathrm{N}$ (2.0\% to $5.0 \%), \mathrm{P}(0.5 \%$ to $1.0 \%), \mathrm{K}(1.0 \%$ to $2.0 \%), \mathrm{Ca}$ ( $0.5 \%$ to $3.0 \%), \mathrm{Mg}(0.3 \%$ to $1.0 \%)$ and $\mathrm{S}(0.2 \%$ to $3.0 \%)$ contents and other micronutrients as $\mathrm{Zn}(15 \mathrm{ppm}$ to 60 ppm), $\mathrm{Cu}$ (4 ppm to $20 \mathrm{ppm}), \mathrm{Fe}$ (500 ppm to $1200 \mathrm{ppm}$ ), 
Mn (20 ppm to $60 \mathrm{ppm})$. Therefore, the neem fruit is very important substances for an organic farm. Cold press extraction method widely extracts the neem oil. This production method needs to dry materials which contain 7 $9 \%$ of moisture content. The neem fruit in other countries could be dried at the sun. However, maturation of late season as in our country needs to artificial drying. In the study, the neem fruits were dried at cabinet drying after sun drying of one week.

This study focus on azadirachtin amount of neem fruit will be subjected to drying, crushing, and extraction of neem oil. Therefore neem fruit was dried firstly at infrared drier then the oil is extracted by solvent extraction method. And some chemical properties of neem fruit were determined. The Scientific and Technological Research Council of Turkey donated the project.

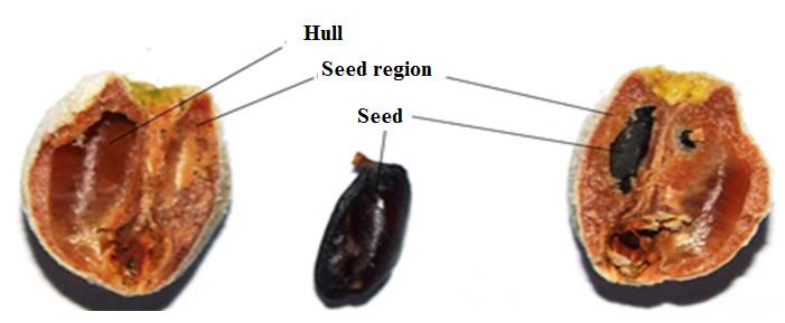

Fig. Structure of neem seed (Melia Azaderach L.)

\section{Material and Methods}

\section{Drying Process}

Neem fruits were locally collected from Cukurova University campus which lay on Cukurova valley in ADANA (TURKEY) province. The fruits were picked-up dried for one week at sun-light. Then the fruits were subjected to the infrared drying at $70^{\circ} \mathrm{C}$ (Fig. 2, 3). The dryer has PID devices which cut the electricity getting information from the inside thermocouple. Three fans were adjusted to the cabin to take moisture outside from the drying chamber with a heat exchanger which helps to protect the detached ingredient from fruits. Before and after the drying process, moisture content was obtained by moisture analyser (Erdem, 2012).

\section{Drying Chamber}

The neem fruits were dried at new-developed infrared drying (ID) methods in a cabinet dryer (Fig. 3). The dryer has 24 infrared heaters (totally $48 \mathrm{~kW}$ outpower) which are located in the middle of the cabinet. The heaters are moveable and scan the hole tray from one side to the other side. During the movement, every fruit is heated by direct radiation. Therefore it is expected that it could be the shortened the drying times and cause a low electricity consumption (Fig 2, 3). The operation is controlled with PID (Polly İnterval Devices) devices and thermocouple to fix the inlet temperature.

\section{Oil Extraction}

For the hexane extraction method, dried neem fruit was crushed by milling in size of $0.5 \mathrm{~mm}$ particle size. The seeds were extracted by soxhlet apparatus to assess the total oil yield. The data were calculated as a mean of three replications.
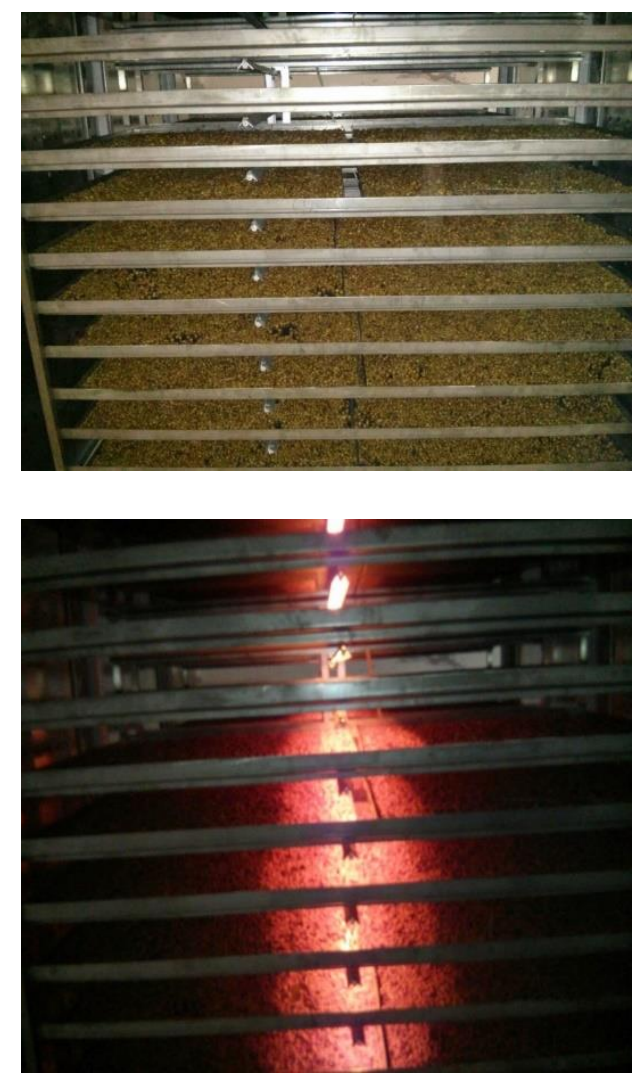

Fig. 2 Neem fruit at drying chamber in an infrared cabinet dryer
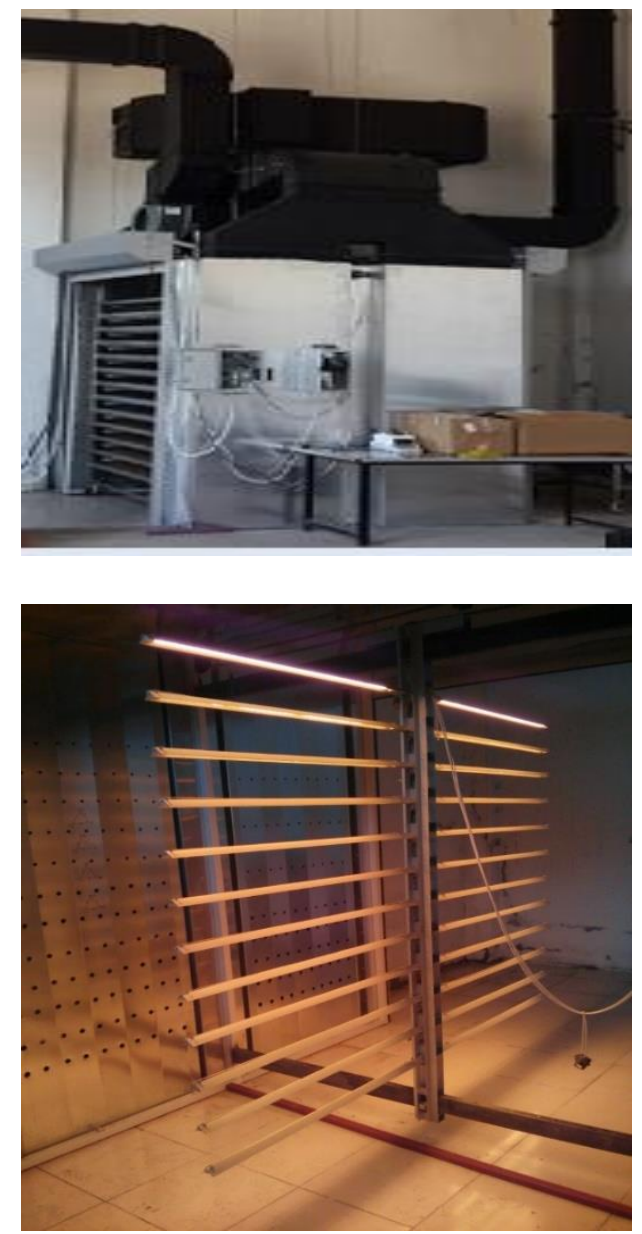

Fig. 3 İnfrared Cabinet Dryer 


\section{Azadirachtin Analyses}

The Total Azadirachtin (AZ) amount is determined by Dichloromethane method (K1z1ldag et al., 2014). The following procedure was done systematically. The dichloromethane solution $(0.7 \mathrm{~mL})$ of standard $\mathrm{AZ}$ or neem seed extract was added a methanol solution $(0.2 \mathrm{~mL})$ of vanillin $(0.02 \mathrm{mg} / \mathrm{mL})$. After shaking manually, the mixture was left at room temperature for $2 \mathrm{~min}$. Concentrated sulfuric acid $(0.3 \mathrm{~mL}, 98 \%)$ was then added in three portions $(0.1 \mathrm{~mL}$ each $)$, and the mixture was stirred for $10 \mathrm{~s}$ after each addition. After the addition of sulfuric acid was completed, methanol $(0.7 \mathrm{~mL})$ was added to convert the two-layer mixture into a homogeneous solution that instantly developed a blue-green colour. The solution was left at room temperature for $5 \mathrm{~min}$ before the absorbance was measured at $577 \mathrm{~nm}$, using a Thermo UVVis Spectrophotometer equipped with a $10-\mathrm{mm}$ quartz cell. The blank solution was obtained by substituting the test solution with an equal volume of dichloromethane in the above procedure. Total azadirachtin in the neem seed extracts (concentrations as stated under Extraction Procedures) was quantified using a calibration curve $\left(\mathrm{R}^{2}\right)$ 0.9995) generated from standard AZ solutions in dichloromethane (0.01-0.10 mg/mL).

\section{Macro and Micro Element Analyses}

ICP-MS (Agilent, 7500a) was used. To the sample preparation, $0,5 \mathrm{~g}$ (dry mass) of fruit sample was weighed into the digestion vessels. Then $10 \mathrm{~mL}$ of concentrated $\mathrm{HNO}_{3}$ (Merck) then decomposed at CEM Mars 5 model microwave oven (CEM Corporation Matthews, NC, USA).

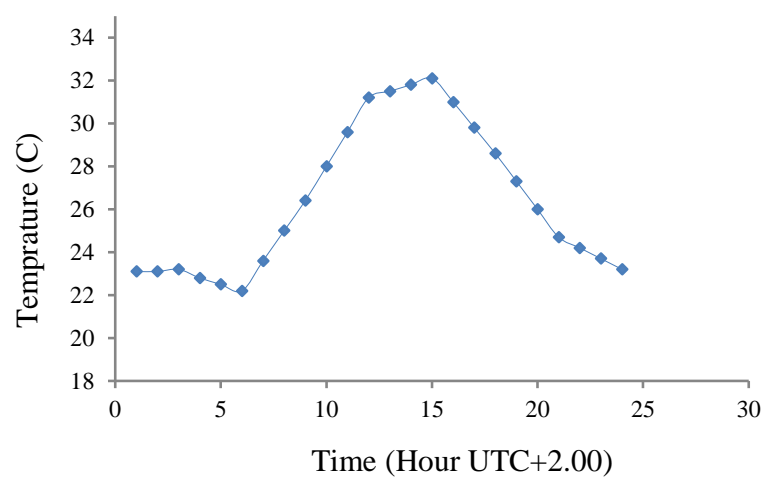

Fig. 4 Daily temperature of duration of sun drying
The fruit samples were digested according to the following optimized program (power in W / time in min): 1200/28, ventilation 10

$0 \mathrm{~min}$. The internal temperature was limited to $180^{\circ} \mathrm{C}$ during the last step and ventilation. After cooling the entire digest were transferred into $50 \mathrm{~mL}$ plastic bottles and diluted to $50 \mathrm{~g}$ with double deionized water and centrifuged at $4000 \mathrm{rpm}$ in $30 \mathrm{~min}$. Reagent blanks were prepared similarly to the samples. All sample solution was clear and diluted ten times before analysis.

\section{Results and Discussion}

The sun drying of neem fruit lasted for one week. The daily irradiation and daily temperature of the drying process were seen in Fig 4. and Fig 5. The neem fruit drying was performed in the cabinet dryer, and its drying parameters are shown in Table 1 and Fig 6 to 8. The drying curves are obtained with dry basis moisture content. The initial moisture content and final moisture content is determined.

Drying of neem fruits was performed as two-step application. The neem fruit was collected in September and left for sun drying for one week. They are then dried at cabinet dryer because of the impossibility of sun drying for mass production. The drying parameters of neem fruits are shown in Table 1 and Table 2.

The neem oil (Fig. 6) is extracted from Melia azedarach, and neem powder is obtained from dried fruits. Some chemical properties and AZ in the powder analyses datum are given Table 3 .

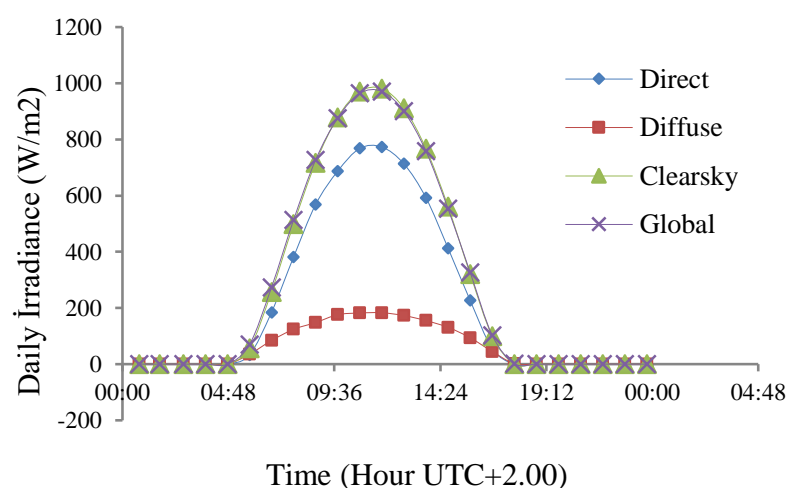

Fig. 5 Daily irradiation of duration of sun drying

Table 1 Drying time versus MC, DR, and MR of neem fruit

\begin{tabular}{l|rrr}
\hline Time, Hour & MC & DR & MR \\
\hline 0 & 0.5625 & 0 & 1 \\
1 & 0.476597 & 0.232135588 & 0.118926 \\
2 & 0.388507 & 0.238044494 & 0.096945 \\
3 & 0.317598 & 0.191617376 & 0.079251 \\
4 & 0.248563 & 0.1865526 & 0.062024 \\
5 & 0.182652 & 0.178111306 & 0.045577 \\
6 & 0.113305 & 0.187396729 & 0.028273 \\
7 & 0.048331 & 0.175578918 & 0.01206 \\
\hline
\end{tabular}

Table 2 Drying of neem fruit parameters

\begin{tabular}{l|ccc}
\hline \multicolumn{1}{c|}{ Drying Type } & Drying Time (h) & İnitial MC (w.b. \%) & Final MC (w.b. \%) \\
\hline Sun Drying (SD) & 168 & 45.56 & 36.00 \\
İnfrared Drying (ID) & 7 & 36.00 & 4.46 \\
\hline
\end{tabular}


Table 3 Dried neem fruit Azadirachtin and other elements analysis

\begin{tabular}{|c|c|c|c|}
\hline & Average & Standard Deviation & Variation \\
\hline Carbon $(\mathrm{C}, \%)$ & 57.52 & 57.166670 & 2.647741 \\
\hline Nitrogen $(\mathrm{N}, \%)$ & 1.34 & 1.343333 & 0.005774 \\
\hline Phosphorus $(\mathrm{P}, \%)$ & 0.170 & 0.184333 & 0.013204 \\
\hline Potassium (K, ppm) & 136.4 & 137.53330 & 7.464806 \\
\hline Calcium (Ca, ppm) & 29 & 29.33333 & 0.288675 \\
\hline Magnesium (Mg, ppm) & 4.96 & 5.17333 & 0.201329 \\
\hline $\operatorname{Iron}(\mathrm{Fe}, \mathrm{ppm})$ & 0.645 & 0.697 & 0.048497 \\
\hline Zinc (Zn, ppm) & 0.425 & 0.395 & 0.03 \\
\hline Azadirachtin contents $(\mathrm{mg} / 100 \mathrm{~g})$ & 46.1 & 46.63333 & 1.569501 \\
\hline
\end{tabular}

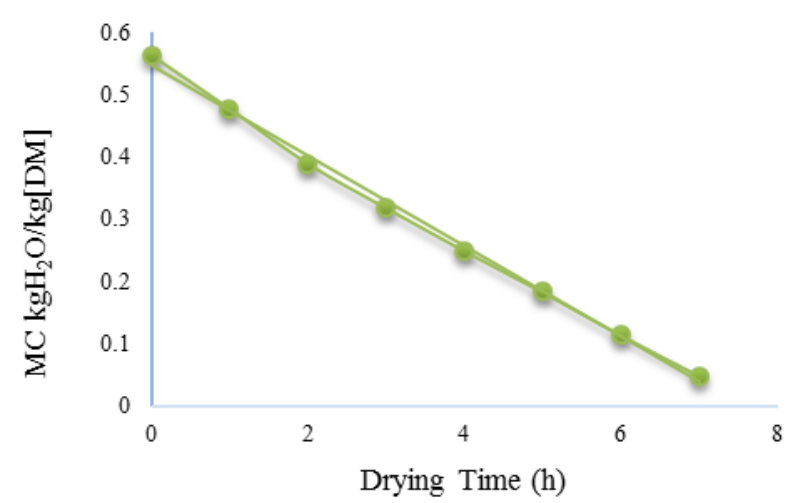

Fig. 6 Drying time \& MC of neem fruit at infrared drying $\left(70^{\circ} \mathrm{C}\right)$

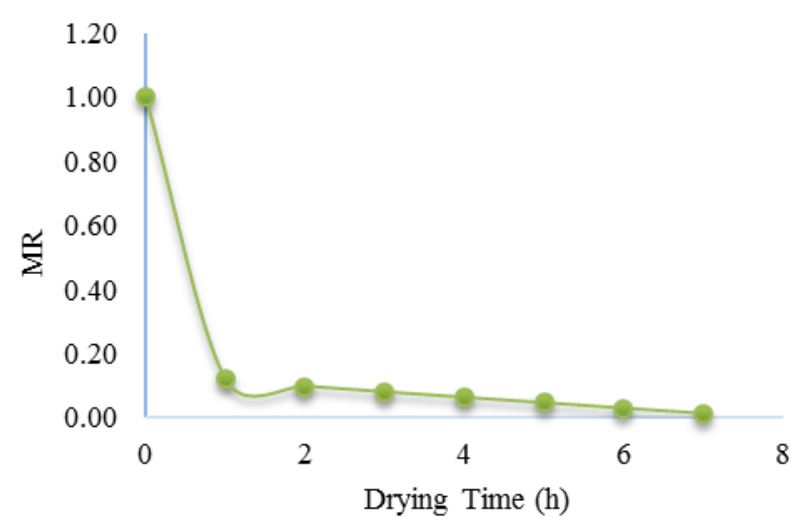

Fig. 8 Drying time $\&$ MR of neem fruit at infrared drying $\left(70^{\circ} \mathrm{C}\right)$

Extracted neem oil yields (Fig 9) from fruits were $14 \%$ of dry basis. The neem oil yield could be double in Melia seeds by comparing the whole fruits. The Melia fruits have small seeds than Azadirachta Indica fruits. Thus the oil yield in Melia fruits is lower than Indica. The neem oil yield that can be obtained from neem seed kernels form Azadirachta Indica varies widely in the literature from $25 \%$ to $45 \%$. (Anonymous, 2016 ${ }^{\mathrm{a}}$, Munoz et. All., 2007, Anonymous, 2016 ${ }^{\mathrm{b}}$ )

Some researcher in early studies has also evaluated the azadirachtin compound of neem fruit. Kizildag et al. (2014) found that Azadirachtin amount of neem fruit which was collected in August and reported that $0.29 \mathrm{mg} / \mathrm{g}$. Azadirachtin results in our current study were found high approximately two times from previous studies. This results might be explained by suitable neem fruit collect

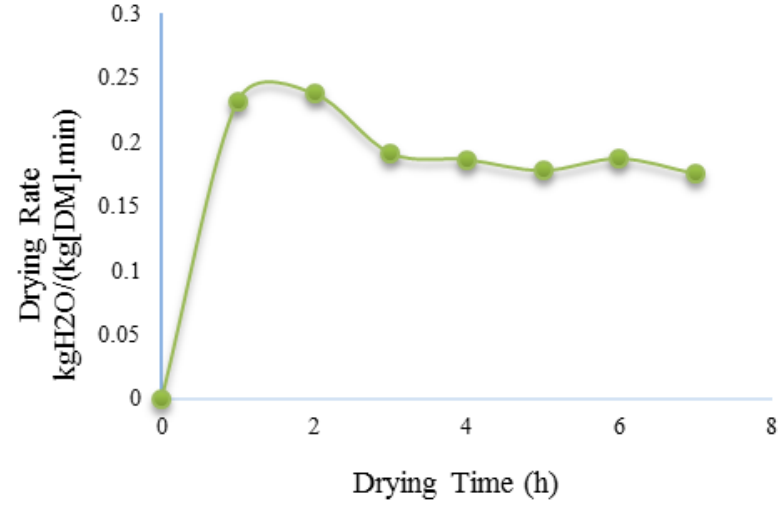

Fig. 7 Drying time\& drying Rate of neem fruit at infrared drying $\left(70^{\circ} \mathrm{C}\right)$

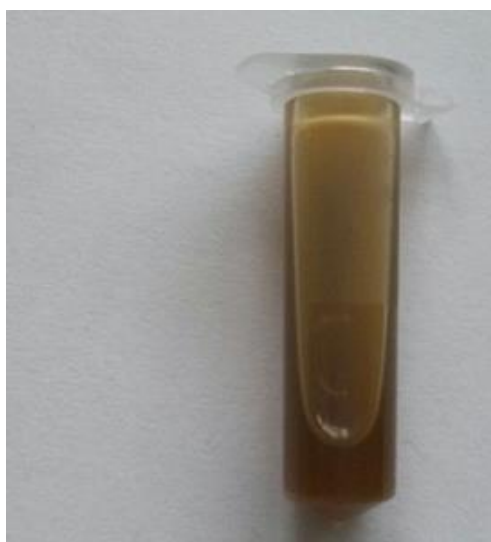

Fig. 9 Neem oil extracted from Melia azedarach

season. As we now, ambient temperature and harvest season affect the oil yield and its concentration. The earlier collection could be the main result of this output data. Seasonal effect on neem oil content was underlined by Elteraifi and Hassanali (2011). They reported that Azcontent ranged from $1.08-2.3 \mathrm{mg} / \mathrm{g}$ of the seed kernel in the first season and from $0.48-3.09 \mathrm{mg} / \mathrm{g}$ in the second season. The average content of neem oil was $44.6 \%$ in the neem seed kernel. However, these results show that Melia Azaderach contents lower Azadirachtin amount comparing to Azadirachta Indica. The Azadirachtin content of Neem oil obtained from Azadirachta Indica can vary a lot from $300 \mathrm{ppm}$ to over $2,500 \mathrm{ppm}$ depending on the extraction and quality of the Neem seeds used to produce the oil (Anonymous, 2016). Supriya Dubhashi et al. (2013) also reported that the Azadirachtin amount of Indica was 35- 
$89 \%$ of seed kernel. The AZ content of NSK (neem seed kernel) also differs seasonally. Elteraifi And Hassanali (2011) reported that Az-content ranged from 1.08 - 2.3 $\mathrm{mg} / \mathrm{g}$ of the seed kernel in the first season and from 0.48 $3.09 \mathrm{mg} / \mathrm{g}$ in the second season. The average content of neem oil was $44.6 \%$ in the neem seed kernel.

The other issue of neem oil process is drying. Drying of agricultural and bioproducts by infrared energy has been researched some other scientist. The main advantage of this type of drying is shorter drying time, which results in the more protected bio-product. Erdem (2012) studied the drying of Laurel berry fruits by infrared drying, and it's reported that infrared drying of Laurel berry fruits has better fatty acid components than hot air and microwave drying.

\section{Conclusion}

The Azadirachtin amount of Melia azaderach L is related to harvesting time and temperature. The neem oil production from Melia azaderach does not seem to be economical. İts oil yield is lower than the Indica, and Azadirachtin amount is as well. Therefore the neem oil production from Melia azaderach in Turkey is not suitable due to needs of artificial drying and its low oil contents and Azadirachtin amount.

\section{References}

Anonymous, 2016a. http://essentialoils.co.za/neem-oil.htm Anonymous, 2016bhttp://www.oilseedcrops.org/wp-content/uploads /2012/11/Indian-Neem-Growth.pdf

Anonymous, 2016c. https://en.wikipedia.org/wiki/Neem_oil

Anonymous, 2012.http://www.ozonebiotech.com/neemoil.html ?gclid=CLmwhaCT07MCFc2R3godWEoA

Erdem T. 2012. Research on Drying Techniques To Obtain Berry Oil From Laurel (Laurus Nobilis L.). Ph.D. theses, Cukurova University Institute of Natural And Applied Sciences Department Of Agricultural Machinery.

Elnour IE, Hassanali A. 2011.Oil and Azadirachtin contents of neem (Azadirachtaindica A. Juss) seed kernels collected from trees growing in different habitats in Sudan. Int. J. Biol. Chem. Sci. 5(3): 1063-1072.

Kızıldağ N, Cenkseven Ş, Aka Sağlıker H, Darıcı C. 2014. "Effects of Melia azedarach L. Leaf and Fruit Addition on Soil Carbon Mineralization", Bangladesh Journal of Botany 43(1): 119-122.

Orwa C, Mutua A, Kindt R, Jamnadass R, Simons A. 2009. Agroforestree Database a tree reference and selection guide version 4.0 (http://www.worldagroforestry.org/af/ treedb/)

Puri HS. 1999. Neem-The Divine Tree. Harwood Academic Publishers, Amsterdam.

Sergio MV, Alberto AIL, Luis MM, RS, Humberto VD, Jesús BF. 2007. Neem Tree Morphology and Oil Content. https:// hort.purdue. edu/newcrop/n cnu07/pdfs/munoz126-128.pdf

Dubhashi S, Pranay V, Singaiah M, Satwik J. 2013. Studies on extraction and HPLC analysis of azadirachtin from kernels of neem seeds. Journal of Advanced Pharmacy Education \& Research Jan- Vol 3 Issue 1 pg; 27-30.

Skellon JH, Thorburn S, Spence J, Chatterjee SN. 1962. The fatty acids of neem oil and their reduction products. J. Sci. Food Agr. 13: 639-643. 